\title{
EL INFORME UTEC
}
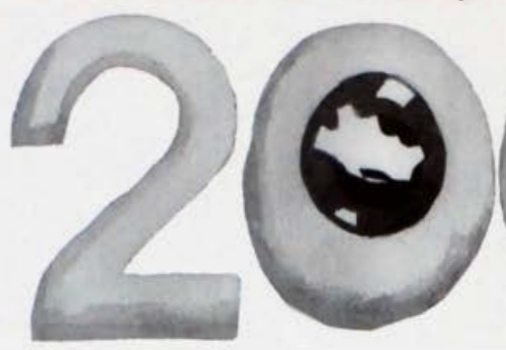

El informe UTEC del año 2001

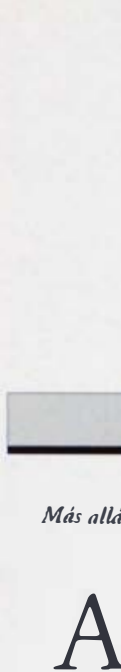

\section{La Economía Salvadoreña} orden fundamental e integral, que padece el pais y que trasciende lo económico. En el área especificamente económica, después de la aplicación de los ajustes estructurales, la liberalización, la privatización, la modernización del Estado y otras formulas de aplicación universal, sugeridas por autoridades exógenas al pais, la opinión particular con respecto a las expectarivas que se tenían sobre los esperados resultados de tales reformas, han pasado del fervor a la frustración.

Las características económicas ya no encajan exclusivamente con las de un fenómeno momentáneo, cíclico o pasajero, de rasgos desfavorables, como podrian ser: un incremento de la deuda externa, un mayor déficit fiscal; o favorables, como una menor inflación, una menor tasa de interés o un tipo de cambio fijo; más bien son de orden estructural.

Mucho se ha pregonado el concepto de una estabilidad macroeconómica, que es identificable con una estabilidad monetaria o de precios. Esa estabilización se ha visto asociada a una inflación reducida, una tasa de interés baja y un tipo de cambio fijo. Sin embargo, el concepto ha resultado un tanto ampuloso, considerando que actualmente los problemas coyunturales de mayor preocupación son la deuda externa e interna y el déficit fiscal, por lo que la estabilidad tampoco encaja con el calificativo de financiera.

Esa estabilización no ha redundado, como era de esperarse, en un crecimiento real significativo, ni en un flujo

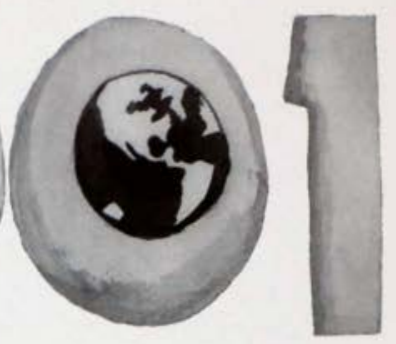

cuantioso de inversión extranjera. Lo que se ha observadoes una declinación en la demanda por una reducción del ingreso real, que ha contrarrestado los incentivos de menores $y$ estables precios de los bienes, del dinero y de las divisas.

Una estabilización macroeconómica en el sentido estricto debería propiciar una reactivación de la economía nacional, cuando la estabilización financiera(reducida la deuda y el déficit fiscal), no dejará en el olvido las posibles fuerzas motrices que subyacen en los sectores productivos que tradicionalmente han incrementado la oferta y la demanda en > ᄀtepaís, y que se encuentran menos favorecidas por el sistema financiero por falta de recuperación y rentabilidad.

Con un crecimiento sectorial más equilibrado y con una mayor dinamia del mercado interno, basada en la generación de desempleo y un incremento en la demanda efectiva, lograriamos nuevamente una auténtica estabilización macroeconómica y un crecimiento sostenido que abarque los renglones productivos que albergan altos porcentajes de la población, como la pequeña y la mediana empresa, el informal y el agropecuario, sectores que podrían consolidar el tejido productivo de la economia interna, corregir el desempleo estructural agrario y urbano, y por ende, recuperar el poder de compra del mercado interno.

Lo afirmado anteriormente surge del convencimiento de que el ajuste se ha reflejado en un incremento en el desempleo rural y más recientemente en el área urbana. Todo pareciera indicar que los costos de ese ajuste se seguirán extendiendo por la opción financiera con un mayor pago de impuestos a los que siempre tributan, sin aumentar la cobertura impositiva a más contribuyentes o evitar la elusión fiscal y con ello reducir los niveles de evasión que ayudarian a incrementar los niveles de ingreso, más allá de los estimados por las autoridades. En definitiva, no sólo se cerraría la brecha fiscal, sino también permitiria momentáneamente af rontar la carga de las erogaciones por pensiones e incrementar los niveles de inversión pública. 
La recaudación fiscal puede resultar reducida cuando se aplican nuevos impuestos, presionando a la misma base tributaria hasta agotarla. Una forma complementaria de ampliar el universo tributario se lograrla con la generación de agroindustrias localmente ubicadas y un casamiento del gobierno con rodos los sectores productivos, y no sólo con el sector financicro. Ese crecimiento nos generaría un real blindaje de los efectos externos como los que nos generan la pérdida de dinamismo de la economía de Estados Unidos y el temor siempre latente del potencial efecto de los problemas financieros de paises de la región.

La crisis se ha evidenciado en otros aspectos que trascienden el ámbito financiero y económico. Se expresa con masivas migraciones, más desempleo e incremento de la pobreza. Al final de cuentas, el precio del deterioro económico y social de un pucblo lo pagan generalmente los pobres, los que deben convivir diariamente con la violencia. con la delincuencia y con las epidemias. La situación tiene, además de esas características, un sistema de administración gubernamental y político que ya no resiste más la incticacia y no puede ocultar el mal endémico de la corrupción.

En efecto, en adición al desequilibrio productivo y los desajustes financieros, tendrá que atenderse: el desempleo. los bajos índices de educación, la salud y vivienda; los niveles de pobreza, el crimen organizado, la corrupción, la inseguridad jurídica y ciudadana, la ausencia de un Estado de Derecho, etc.
Para alcanzar un bienestar social y abolir el triángulo de desajuste social, producrivo y financiero, se debe visualizar la realidad nacional en una perspectiva pragmática y desposcída de toda connotación pesimista.

La problemática sociocconómica de El Salvador, de hoy, es diferente a lo que era hace aproximadamente unos 25 años, cuando empezaron hacerse evidentes insatislacciones y rensiones sociales en el país. Fue en aquella época en que se anunciaron algunos intentos de reformas económicas por parte del gobierno con propósitos sociales; intentos que pasaron al ensayo, pero que en definitiva no lograron cimentar las bases productivas que posibilitaran un crecimiento sostenido.

Se logró un crecimiento en la primera década de los noventa por la expansión de una demanda reprimida por la guerra inrerna de los ochenta; pero éste impulso se agotó y no se tradujo en beneficios colectivos a través de proyectados programas de compensación social que se pregonaron en forma insistente $y$ hasta demagógica, $y$ no pasaron de ser un enunciado o se constituyeron en programas de ajuste que siempre acabaron socializando los costos.

Muchas de las reformas que durante una década se han aplicado en toda América Latina y en El Salvador, están mostrando signos de debilidad, surgidas como una reacción al fracaso de un Estado benefactor y a un modelo de industrialización proteccionista. Estas reformas dieron lugar a las privatizaciones; apertura a la inversión extranjera, la flexibilización de los mercados laborales, el control de la

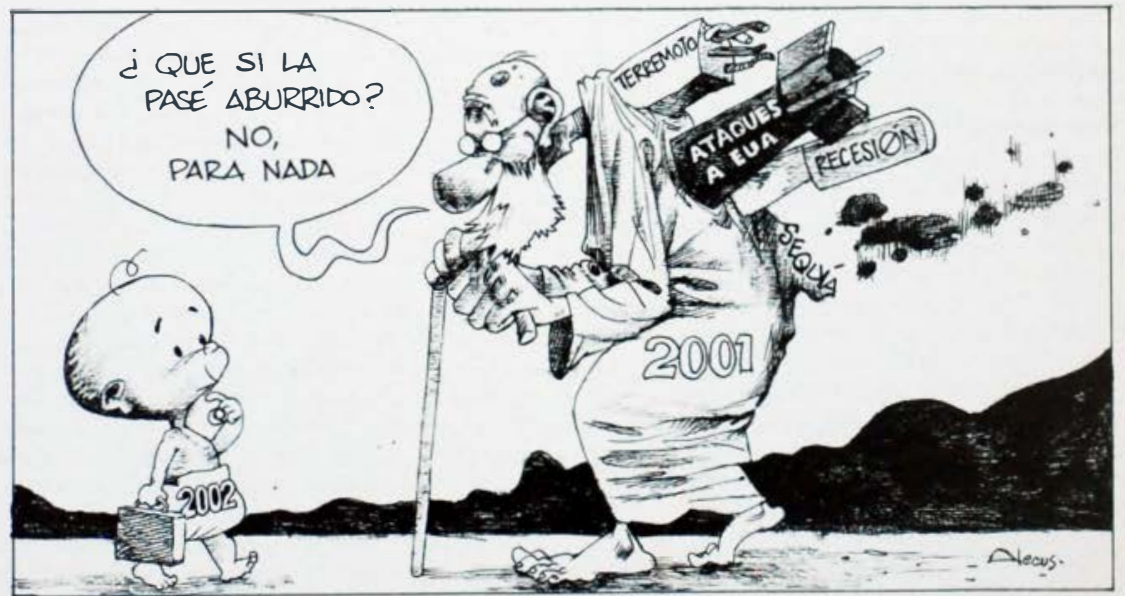

Entorno ISSN: 2218-3345 
inflación, mediante una severa política monetaria (o de ambas) y el propósito de conformar un Estado más pequeño, moderno y cficaz.

Respaldadas con entusiasmo por el Fondo Monetario Internacional y el Banco Mundial, se pronosticaba que tales reformas, en compañía de una democracia, una política de compensación social y una estabilidad política, acelerarían elcrecimientoeconómico y un bienestar generalizado. Como se mencionó en el primer quinquenio hubo crecimiento. Pero los factores impulsores del crecimiente) tendieron a debilitarse en el segundo quinquenio y a pesar de las privatizaciones, la apertura a la inversión extranjera, la estabilidad monetaria y los esfuerzos aislados de modernización del Estado, el crecimiento y el progreso de la mayoría no se ha manifestado.

Hoy en día nadie puede negar la presencia de un estancamiento, pero también la existencia de diferencias extremas en la distribución del ingreso y en la concentración de la riqueza. Esa desigual distribución vuelve ineficaces las supuestas intenciones de convertir el crecimiento en beneficio generalizado, debido a la existencia de un monopolio social en el cual los grupos sociales dominantes en la actividad económica, a su vez, ostentan el mancjo del andamiajc político.

Esas desigualdades son cultivo de tensiones sociales que al no atenderse oportunamente, a veces llegan a la exacerbación, no debiendoignorarse que en ciertas ocasiones son explotadas ideológicamente, a fin de propiciar conflictos que terminan por destruir las fuentes de riqueza y de trabajo, empeorando de csa mancra la situación.

\section{La crisis fuera de un despacho}

on pocos, quizás, los que concientemente niegan o

desconocen la realidad de la calle, del barrio $y$ de las zonas marginales. Su reconocimiento explícito, lo ha hecho público el Señor Presidente de la República, quien está consciente de ello, desde mucho antes del principio de su gestión y ha expresado reiteradamente el objetivo de combatir la pobreza.

De igual manera se ha venido dando prioridad a la necesidad de llevar a cabo programas sociales, a fin de sarisfacer las necesidades básicas de los grupos más desposeídos. El país, económicamente hablando, necesita crecer y agrandar el pastel económico (su producción), ya que si no se produce más, afirma que se va a distribuir mejor cl ingreso, son fantasias engaiiosas o hablar demagógicamente. Lo que sí se debiera de capitalizar son los crrores del pasado, y si se lograra una reactivación económica, se debe asegurar, y esta vez en forma palpable. que una parte significativa de la población supere las condiciones precarias de subsistencia.

La crisis sociocconómica del presente es un conjunto entrelazado de problemas, los cuales han llegado a una fase de malestar todavía oculto o reprimido. Salvo la delincuencia que ya es un signo evidente de la aceleración de la misma. Esos grandes problemas de El Salvador en el presente son su pobreza extrema, sus agudos desequilibrios sociales, su estancamiento productivo, la escalada de precios de servicios básicos, su subdesarrollo institucional, la inseguridad ciudadana y la falta de un ordenamiento juridico.

Esas posibilidades están supeditadas a muchos factores de difícil concreción en el corto plazo, ya que tienen que ver con una expansión y diversificación de la oferta, fundamentada en un consumo interno y externo. Además, en una inversión interna sostenida y en áreas selectivas de maduración productiva efectiva y generadora de empleo masivo; de igual forma, en infracstructura social que facilite una mejora en los servicios de educación y salud.

Un paréntesis necesario. La inversión en infracstructura y servicios de educación es impostergable cuando se observan algunos de los problemas endémicos que padece la sociedad salvadoreña: la delincuencia, machismo, alcoholismo, drogadicción, corrupción privada y gubernamental, las pandillas callejeras y hasta los buseros irresponsables, se concluye y con razón que "educación es la solución".

La generación de nuevas oportunidades de empleo, es tan importante para la reactivación económica, como un Estado de Derecho, que se traduzca en una seguridad juridica y ciudadana, lo es para la estabilidad social. Por otra parte, si no hay un cambio favorable en nuestras actitudes $y$ responsabilidades, y si no se cambia la concepción de que "El Estado tiene que propiciar el bien de todos y no ponemos nada de nuestra parte", muy poco se logrará para un auténtico desarrollo.

En resumen la real crisis es el insuficiente crecimiento del producto, del ingreso, del ahorro y de la inversión; la deceriorada capacidad productiva de sectores tradicionalmente generadores de empleo y de divisas; la reducida y poca diversificada estructura exportadora; la casi nula comperitividad; el rezago tecnológico; la dependencia extrema de las remesas familiares; el desempleo estructural agrario; el lastre del deterioro ecológico; la incompetencia institucional; la inseguridad ciudadana; las deficienciaslegales que derivan en un deterioro jurídico; la ausencia de un Estado de Derecho, etc. La presencia de esos ingentes problemas conforman la crisis fundamental. 


\section{El pasado reciente}

Coyunturalmente se ha vuelto hablar de indicadores de corto plazo que tienen que ver con la corriente real y financiera, tales como: el crecimiento del Producto Interno Bruto (PIB), inflación, nivel de exportaciones, nivel de importaciones, captación de ingresos fiscales, niveles de gastos públicos, niveles de depósitos y de créditos en el sistema financiero, como si su momentáneo ascenso o descenso fuese sinónimo de estabilidad y beneficio colecrivo. El comportamiento de esas variables podrá afectar los eventuales beneficios o pérdidas de pocos, pero de ninguna manera viene a cambiar la suerte de las mayorías.

Como se afirma en la publicación de la UTEC con motivo de sus 20 años: "El Salvador del Futuro, Una Visión Académica", con cuanto abuso se acude al lenguaje de la economia para definir el rumbo y las metas de la sociedad envolviendo en guarismos, el drama humano y desolador de las sociedades pobres.

Definimos el crecimiento de la economía en términos de porcentajesde crecimiento anuales del PIB, pero olvidamos qué porcentajes de nuestros habitantes permanecen sometidos a un régimen de economía infrahumana; nos ufanámos de que nuestro PIB per cápita es superior al de Uganda. Somalia y muchos otros de los países del tercer mundo, pero queremos ignorar las tremendas desigualdades de ingresos entre nuestros ricos y nuestros pobres.
Hablamos y medimos el bienestar en automóviles, aparatos de televisión, teléfonos celulares, en la ingesta de calorías o cualquier otra refinada modalidad de comparación, pero ocultamos que en el reparto social de la producción anual de bienes y servicios no todos reciben lo mismo. La esperanza de vida, la salud, las oportunidades de educación y trabajo no son las mismas para todos en las sociedades pobres. Y rodavia mucho menos en las sociedades desiguales.

Destaca dentro de ese contextu estrictamente económico la incapacidad del sistema productivo para recuperar su capacidad de generación de empleo y un crecimiento sectorial equilibrado. Preocupa un sector primario desalentado por la baja remuneración que recibe por el producto generado, un sector manufacturero con una leve recuperación después de un estancamiento, un sector comercio que pierde dinamismo, un sector construcción que presenta una eventual, aunque todavia leve, recuperación y un sector financicro en el cual no todas las instituciones que lo integran presentan los mismos ritmos de solvencia y liquidez.

Es de relevancia destacar el sistema bancario que creció en el 2001 en ganancias, patrimonio y activos. Cuatro entidades siguen dominando el mercado $y$ otras cuatro obtuvieron pérdidas. Un crecimiento de 12 por ciento en los activos y de $8.2 \mathrm{en} \mathrm{el} \mathrm{patrimonio,} \mathrm{deja} \mathrm{el} \mathrm{balance} \mathrm{al} \mathrm{cierre}$ del 2001

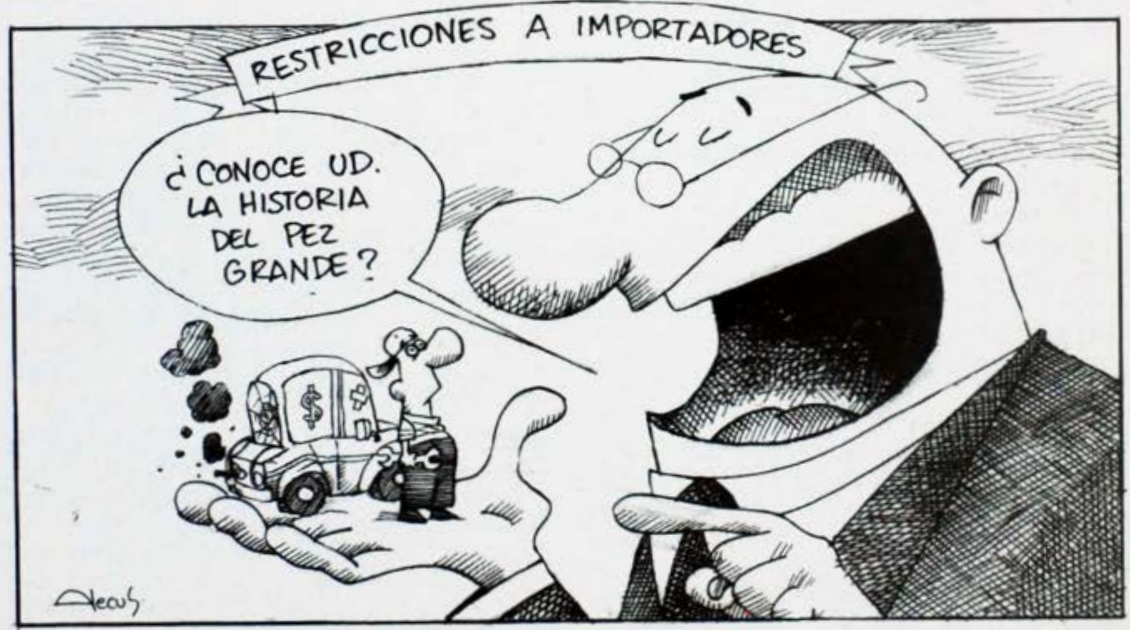

Entorno ISSN: 2218-3345 
(1) (17)

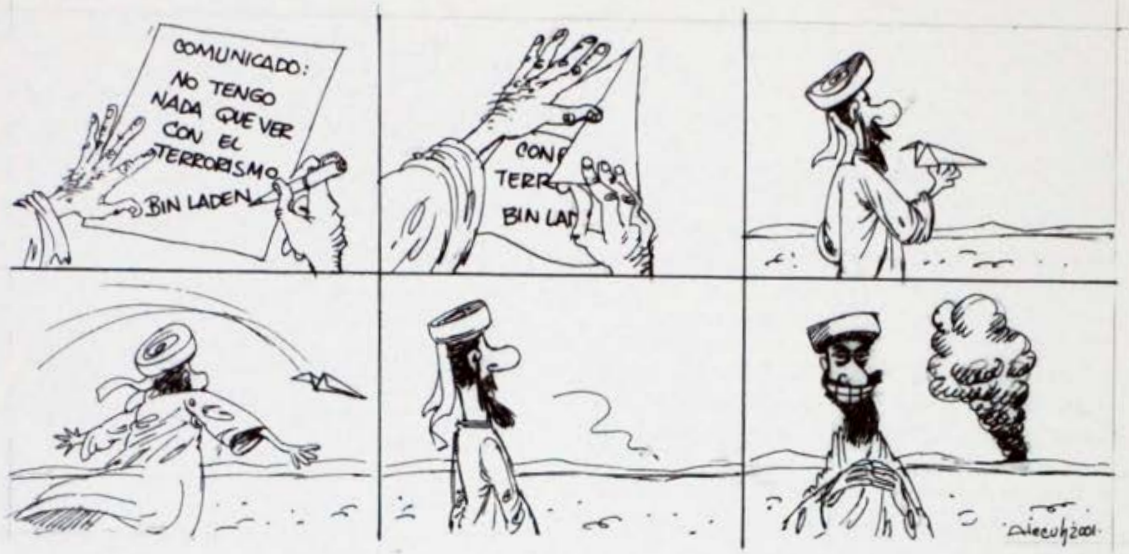

También destaca un sector externo con un desbalance comercial que se ensancha, debido en gran parte a una pérdida cada vez mayor de los términos de intercambio, simbolizados por un producto de exportación: el café y otro de importación: el petróleo; con una maquila a la cual se le ha apostado y se le ha confiado buena parte de la dinámica de las exportaciones a pesar del riesgo de ser una industria muy susceptible a emigrar a lugares donde se ofrezcan menores costos de producción.

A pesar de la eventualidad de crecimiento de las exportaciones y una evidente falta de garantía de sostenibilidad de ese incremento, la propensión media a importar, se ha mantenido en los últimos años, debido al creciente fujo de remesas familiares y más recientemente al endeudamiento resultante de las gestiones de financiamiento externo para la reconstrucción.

En materia fiscal el gobierno después de haber experimentado un incremento en el déficit fiscal y estar consciente de la necesidad de aumentar sus gastos en infraestructura fisica y social, ha decidido implementar un ambicioso programa de control y supervisión en el cumplimiento de las obligaciones a fin de lograr incrementar los ingresos fiscales; estrategia en la que se destaca las auditorias de sistemas informáticos y la supervisión de las compras gubernamentales. Otros programas tienen que ver con la revisión de la emisión de facturas, el control de inventarios y la fiscalización de las exportaciones.
La atención que aparentemente las autoridades económicas le están prestando a las finanzas públicas surge del hecho que el Gobierno Central tiene el problema de atender flujos crecientes de compromisos por servicios de deuda, costo previsional y componentes de gasto inflexible, lo cual significa que los márgenes de gestión del gasto público se están reduciendo por el ahorro corriente negativo, y por tanto, las posibilidades de destinar recursos a obras de inversión, lo que pone restricciones importantes a la gestión fiscal, que se ve obligada a contraer deudas.

La sostenibilidad fiscal que ya era relevante antes de los terremotos, se ha vuelto, como lo aseveró la Fundación Salvadoreña para el Desarrollo Económico y Social (FUSADES), un tema obligado en la agenda urgente de las autoridades de gobierno en un contexto que procura viabilidad económica de mediano y largo plazo. "Los niveles de endeudamiento crecen aceleradamente entre los años 2001 y 2002. Pero también se ha limpiado la mesa de deuda de corto plazo, lo que facilita la gestión del servicio de deuda de los próximos años.

En todo caso, el tema de sostenibilidad fiscal está por definirse, y en el que están en juego no solamente variables fiscales como el déficit fiscal, el nivel de endeudamiento y su servicio, sino también la tasa de crecimiento real de la economía, la cual depende de diversos factores $y$ del concurso de los agentes económicos." 
El rendimiento promedio de los bancos se ha mantenido en términos de su rentabilidad, a pesar que algunas instituciones estatales $y$ algunos pequeños intermediarios financieros han presentado problemas de liquidez, solvencia y de recuperación.

Sin embargo, la alta rentabilidad que registran, por lo menos dos bancos que controlan más de la mitad de las operaciones, sitúan siempre a este sector como el más dinámico de Centroamérica. La caída en las tasas de interés no ha significado un incremento sustantivo en los niveles de crédito.

La falta de acceso a ese crédito de personas naturales y juridicas $y$ un desaliento en algunos inversionistas no ha posibilitado una expansión significativa del mismo, como era de esperarse. Pese a ello, tasas preferenciales para voluminosos créditos a empresas seleccionadas en una estrategia crediticia selectiva $y$ rentable, le han permitido a ciertos intermediarios conservar su ranking a nivel regional.

Los terremotos y el ataque a los Estados Unidos han sido considerados dos eventos potenciales de una mayor desaceleración de la economía salvadoreña; mayor a la que ya venia padeciendo en los últimos seis años.

Eventualmente un programa de reconstrucción a fuego lento y una aparente y sorpresiva reactivación de la economia estadounidense han posibilitado un crecimiento económico real, pero por debajo del incremento de la población y del necesario para potenciar una reducción de la pobreza. En un contexto de una mejor distribución del ingreso por la via de una mayor captación de impuestos, como se pretende. Acciones factibles de aplicar mientras reformas en la asignación del mecanismo impuesto-gasto puedan politicamente efectuarse.

El temor a un deterioro económico por efecto de los terremotos se basaba en el daño que los sismos provocaron en la planta productiva del país, que afectaron a la agricultura en una proporción relativamente no significativa, a unas pocas plantas industriales $y$ en un mayor grado a la infracstructura vial.

Por otra parte, la dependencia de la economía salvadoreña dela de Estados Unidos es mayor en la actualidad que la de hace 60 años. En los cuarenta, eran el café y otros productos, más adelante se agregó el algodón. Hoy el café presenta serios problemas de sobreproducción mundial y de baja de precios. El algodón dejó de ser un rubro en El Salvador $y$ la estructura productiva de este país hoy es el café, maquila y otros productos. A los cuales se agrega la estratégica fuente compensadora de lo que las exportaciones de bienes no pueden hacer o sea las remesas familiares.

Reiterando el temor latente de los efectos del terrorismo en Estados Unidos, se fundamenta en que la economía salvadoreña, en el presente, es más dependiente de ésta potencia económica que en el pasado; más supeditada de la recuperación de la confianza del consumidor y del inversionista estadounidense. Puede verse afectada en el corto plazo, pero mayormente en el mediano plazo por una menor demanda de los productos que se adquieren en tiempos de paz, sobre todo de maquila.

Las remesas familiares se pueden reducir por la tendencia a que crezca el desempleo en un pais que ha sido la planta industrial más grande de la mano de obra salvadoreña, a lo cual se agrega un giro adverso en la políica migratoria, que contrarrestaria las migraciones futuras y la principal fuente de divisas del pais. También pueden preverse aumentos en las primas de seguros y reaseguros, y una renuencia de nueva inversión extranjera, que no encuentra la estabilidad integral necesaria.

En resumen, el desempeño económico reciente se destaca por una conjunción de factores negativos endógenos y exógenos de carácter eventual y extraordinario, tales como: los terremotos, la sequia, la reducción de los precios del café, los precios desfavorables del petróleo, la baja demanda (interna y externa) y la reducción del comercio por los atentados terroristas de septiembre en los Estados Unidos: sucesos todos que aceleraron e incrementaron la crisis externa e interna respectivamente en el tescer trimestre de año pasado.

Entre los factores anteriores destaca por su carácter extraordinario los ef ectos torre y terremotos, el primero por afectar momentáneamente algunas de las exportaciones. principalmente la maquila, del pais ante la caida del consumo interno de la economía más fuerte del mundo, y el segundo por el daño de la infracstructura familiar y productiva del pais.

\section{Acciones mínimas}

W abrá que fijar en la mente las siguientes premisas

- y limitaciones al momento de proponer soluciones, si se quiere que estas sean objerivas. No hay verdades absolutas, el país tiene limitaciones naturales que le impiden un grado ideal de desarrollo, existe un bajo nivel educacional, una reducida comperitividad, la economía es bastante independiente del exterior $y$ las principales economias del mundo todavía se encuentran en una desaceleración, sobre todo la que más nos concierne y que directamente nos afecta, la de Estados Unidos. 
Todo lo anterior, condiciona las opciones de solución a que éstas sean realistas y que por lo tanto conlleven una alteración de las condiciones actuales hasta donde realmente le sea permisible al pais mismo. Como ya se insinuó al principio de estas reflexiones la crisis trasciende lo económico. La sociedad salvadoreña se ha visto sacudida desde sus cimientos, o sea desde la familia hasta sus otras instituciones claves. Los principios morales y éticos de la clase política se han visto deteriorados. Existe una cultura de corrupción, así como la ausencia de un régimen de derechos y obligaciones.

En el plano de las políticas económicas que no trascienden el corto plazo es preocupante la desaparición de una política monetaria que garantice una disciplina financiera. También es necesaria una política crediticia que estimule la producción de sectores estratégicos y que no sólo enfatice la rentabilidad del prestamista. Una revisión de la política arancelaria se hace también necesaria, considerando la brecha comercial vigente. La revisión puede hacerse extensiva a la estructura tributaria y a la política de gasto, no sólo en función de lograr "cuadrar" el presupuesto, sino hacer de éste un instrumento de política económica con capacidad de generar crecimiento sostenible y equitativo.

Retornando a los problemas fundamentales, la crisis en que nos encontramos inmersos desde hace muchos años, pareciera en rigor o en principio, que carece de solución. Si la pregunta se le hace a una computadora alimentada con las características de El Salvador de hoy, automáticamente ésta diría que el país carece de un mañana. Sin embargo, basta con pensar que la ruina ha llegado no por nuestra mala suerte, sino en gran parte por nuestros propios errores como humanos que somos $y$, siendo más estrictos, por nuestra negligencia y por nuestras actitudes, muchas veces negativas y egoístas. De alli que nuestro destino puede ser alterado favorablemente con una buena dosis de optimismo, cuando haya voluntad polírica y cuando la ciudadanía en general este dispuesta al cambio.

Ahora nos toca afrontar los retos que implican en la práctica la firma de varios tratados comerciales con paises de igual y mayor grado de comperitividad y desarrollo. Si no podemos salir gananciosos con una balanza comercial favorable, por una of erta esencialmente escasa y poco competitiva, al menos deberíamos poder atraer inversión foránea creando en el menor tiempo posible en un contexto de infraestructura física y jurídica idóneo.
El Salvador se encuentra en un punto álgido, en que la dependencia y otras amenazas socioeconómicas, obligan a decisiones trascendentales $y$ a una definición del rumbo al mediano y largo plazo, que permita superar, de una vez por todas, los lastres del pasado.

Los grandes objerivos económicos de la nación deberían ser los siguientes: Un nivel más alto de crecimiento, un apoyo al libre comercio, sin subsidios, ni prácticas desleales y flujos crecientes de inversión productiva, apoyo decidido a la integración económica, una mejor distribución del ingreso, una mejora significativa en el bienestar de la población, una disminución de la pobreza relativa, una erradicación de la pobreza extrema.

\section{«Toda verdad es simple».} duplicada?

Friedrich Nietzsche

organizado, una transparencia de la gestión pública; erradicación de la corrupción a todos los niveles, una transparencia de la gestión gubernamental, una vigencia de un Estado de Derecho, y la construcción de un sistema político justo, equitativo y participativo.

\section{Los Aspectos sociales}

$\mathrm{C}_{\text {manifiestan algunos signos de deterioro, que se }}$ empezaron a manifestar desde hace varios años y que no dan muestras de acciones correctivas para el corto y el mediano plazo. Pareciera que el gobierno supone la existencia de algunas muestras de insatisfacción que no son relevantes y se encuentran mínimamente expresadas en algunos sectores de la población.

Los principales problemas de la sociedad están referidos al desempleo y el escaso poder adquisitivo de las familias de más bajos ingresos. El desempleo es un problema crónico, cuya solución se aleja en el tiempo. Aquí pueden identificarse algunas causas, entre ellas la recesión de la economía, que se refleja en las muy bajas o nulas tasas de crecimiento del Producto Interno Bruto; de 1.8 por ciento para el año 2001 . de acuerdo con las cifras de los sectores oficiales y de la oficina de asesoría económica del gran sector empresarial Fusades. 
Los terremotos del 13 de enero y el 13 de febrero del ańo 2001 , infligieron una signifi-cativa destrucción del patrimonio familiar, las cosechas agricolas, la infraestructura. Así también, las escuclas, hospirales, iglesias y otros edificios. La red vial se vio interrumpida por aludes de tierra que cayeron sobre las carre-teras, en el tramo de Los Chorros en la vía hacia Santa Ana; en la carretera a San Vicente, a la altura de la ciudad y la vía a Comasagua.

La amplitud del sismo fue tal, que dañó todo el territorio de la República. Sin embargo, se reconoce que unas zonas fueron más dañadas que otras. La emergencia fue enfrentada directamente por varios sectores: el gobierno, la gran empresa privada, la fuerza armada, los alcaldes, la iglesia y muchas instituciones de ayuda humanitaria. Los gobiernos de muchos paises enviaron ayuda inmediata, destacándose España, México, Venezuela y Japón. La asistencia humanitaria en manos de los sectores nacionales careció de coordinación y reclamos mutuos, especialmente entre el gobierno y las alcaldías en manos de la oposición, se hicieron en los medios de difusión nacional.

Sin duda alguna estos sismos contribuyeron al agravamiento de las tensiones sociales, mientras se restablecia la normalidad de la acrividad económica. La reconstrucción de las viviendas familiares, los trabajos de reparación de la infraestructura, las obras para aminorar los daños y las acciones para sostener la economia permitieron, a finales del año, una estabilización de las actividades.

Sin embargo, el desempleo continúa siendo el mayor problema de las familias salvadoreñas. Fusades en sus informes sostiene la existencia de una tasa de desempleo del 6.3 por ciento, levemente superior a la tasa de desempleo de la economía norteamericana, calculada en 6.0, para el mismo periodo. Es necesario señalar que, para el caso salvadoreño, esa cifra no comprende los problemas del subempleo, la ocupación disfrazada, el empleo de temporada, los ocasionales y demás categorías de falta de trabajo.

En consecuencia, la falta de empleo significa directamente una carencia de ingresos que afecta los niveles de consumo de la población. La pobreza extrema ha aumentado, lo que significa también un aumento en los otros niveles de pobreza. Declaraciones oficiales dicen lo contrario, sosteniendo que la pobreza extrema se ha reducido; pero hay un evidente contraste entre la posición oficial y la realidad que se palpa en las calles y en los barrios miseria.

Pareciera ser que el indice de precios al consumidor, medido estadísticamente por el gobierno presenta una leve Entorno

ISSN: 2218-3345
«No es de la benevolencia del cervecero ni de la del panadero de lo que esperamos la comida, sino de su preocupación por sus propios intereses.

Nos encomendamos, no a su humanidad, sino a su egoísmo, y no les hablamos jamás de nuestras necesidades, sino de sus ventajas».

Adam Smith tendencia al crecimiento. La opinión generalizada del sector comercio, grandes, medianos y pequeños, acusan una reducción en el nivel de actividad comercial, públicamente expresada por las grandes empresas a finales del año. El peso de la crisis recae sobre las micro y pequeñas empresas principalmente. Muchas de ellas han tenido que retirarse del mercado.

Los despidos masivos en instituciones de gobierno, y también en la empresa privada son del conocimiento público. Se han reformado algunas leyes para obligar a retirarse a muchos empleados con indemnizaciones pagadas parcialmente, y con muy escasas expectativas de reincor-

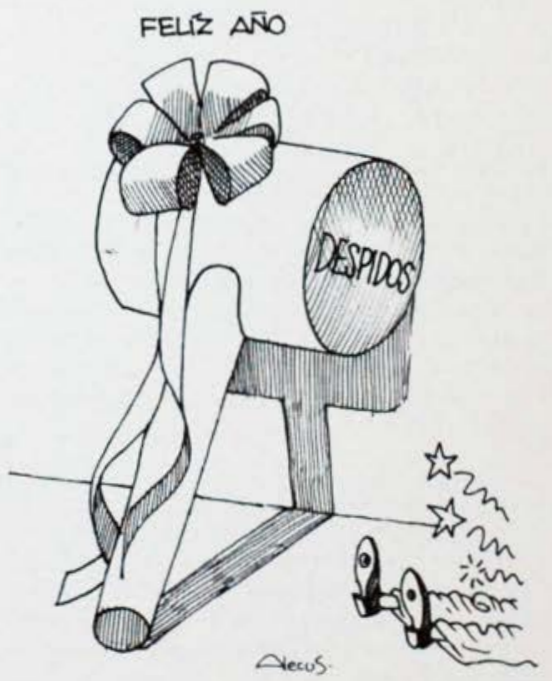

Abril-Mayo 2002, N. 24 
poración a otro empleo. Entonces muy difícilmente podría afirmarse que el período de estancamiento haya sido superado.

La pobreza y el desempleo se convierten en factores de peso en los procesos de descomposición social. Las familias tienen que sobrevivir y eso significa la adopción de opciones fucra de la tradición para conseguir los ingresos. Se destacan entre ellas la corrupción, el contrabando, la prostitución, el pillaje, cl robo, los secuestros y las participaciones en muchas acrividades delictivas.

La crisis de oportunidades, situación que se ha vuclto endémica, es un factor que empuja el fenómeno de migración hacia el extranjero, especialmente a los Estados Unidos, Canada y Australia. Los migrantes de la década de los años ochenta se iban por causa de la guerra civil que asoló el país; actualmente, superada la confrontación civil, el ahogamiento económico, la imposibilidad de conseguir empleo e insertarse en las actividades productivas prácticamente obliga a migrar, asumiendo los altos costos de la aventura, incluida la muerte.

Durante el año pasado aproximadamente 600 salvadoreños viajaron a Suecia en busca de nuevas oportunidades, engañados por algunas Agencias de Viajes, quienes surilmente les of recieron la posibilidad de acogerse a programas de inserción para refugiados políticos. Obviamente, El Salvador ya no es un país en guerra y los criterios para solicitar refugio no les son aplicables. Las autoridades suecas, en forma terminante, han tomado la decisión de repatriar a todos los migrantes, y la aventura termina con su regreso al país. Evidentemente en esta situación cabe señalar que la huida del país ha alcanzado a los sectores de las clases medias. Se sabe de muchas familias que vendieron sus viviendas, automóviles, mucbles, enseres, incluso más de alguno renunció a sus empleos en pos de una mejor suerte.

La migración hacia Estados Unidos es prácricamente indetenible. Los medios informativos dan cuenta a cada momento, de las estafas y sufrimientos de muchos aspirantes a cruzar ilegalmente la frontera. Para medrar en esta aspiración, bandas de delincuentes conocidos como "coyores", cobran aproximadamente 5 mil dólares por persona para ayudarlos a llegar al sueño americano. Tratados bestialmente, abandonados sin misericordia en los trayectos, muertos en los inhóspitos desiertos americanos, capturados por las patrullas fronterizas.
Son muy pocos los que llegan y muchos los que no alcanzan dramáticamente su sueño, como es el caso reciente del policía nacional civil que perdió sus piernas al quedar atrapado entre los rieles y un ferrocarril en marcha.

Para conseguir que las grandes cantidades de ilegales salvadoreños que ya residen en los Estados Unidos no sean deportados, se recurre a la formula simple de aspirar el favor de los políticos norteamericanos para incluirlos en leyes especiales o prorrogar la ampliación de disposiciones, para que permanezcan en dicho país.

Solón

Dos son las preocupaciones básicas de la política gubernamental: en primer lugar, mantener el flujo de las remesas familiares, que actualmente son el primer rubro de ingreso de divisas de la Balanza de pagos, y en segundo lugar, impedir el problema social que significaría que muchísimos trabajadores ilegales regresen al país en busca de empleo o cualquier otra forma de trabajo, y se incorporen a las fuerzas sociales en tensión; pues, sin ninguna duda, se magnificarían la conflictividad social todavía controlada por los aparatos policiales del estado.

Hay muchos conflictos a nivel social que no han sido resueltos. Lo único que se ha hecho es posponer su solución en el tiempo. Aquí hay que referirse al sistema de salud y la tensión existente entre los trabajadores y médicos del Seguro Social y las autoridades respectivas; también se encuentra el conflicto entre los empresarios de autobuses y las autoridades del Viceministerio de Transporte; los despidos de empleados públicos en diversas carteras de Estado y sus indemnizaciones; el problema de la basura y su solución social, los vendedores de las calles de San Salvador y el ordenamiento urbano, el funcionamiento de casinos y su permisividad legal y érica, y otros que enfrentan a sectores empresariales con las autoridades.

Por ejemplo, las horas permitidas para el consumo comercial de bebidas alcohólicas, las plantas de tratamiento de la basura del gran San Salvador, el alto costo de la energía eléctrica, el valor de los pasajes, los precios de los servicios públicos y muchos otros.

Las remesas familiares, además de contribuir a cerrar el déficit de la Balanza Comercial, permiten mantener el consumo de muchas familias desempleadas o mejorar los niveles de consumo de otras familias de menores ingresos.

De sobra se sabe que las familias que reciben divisas del exterior corresponden a grupos familiares de pequeños y 


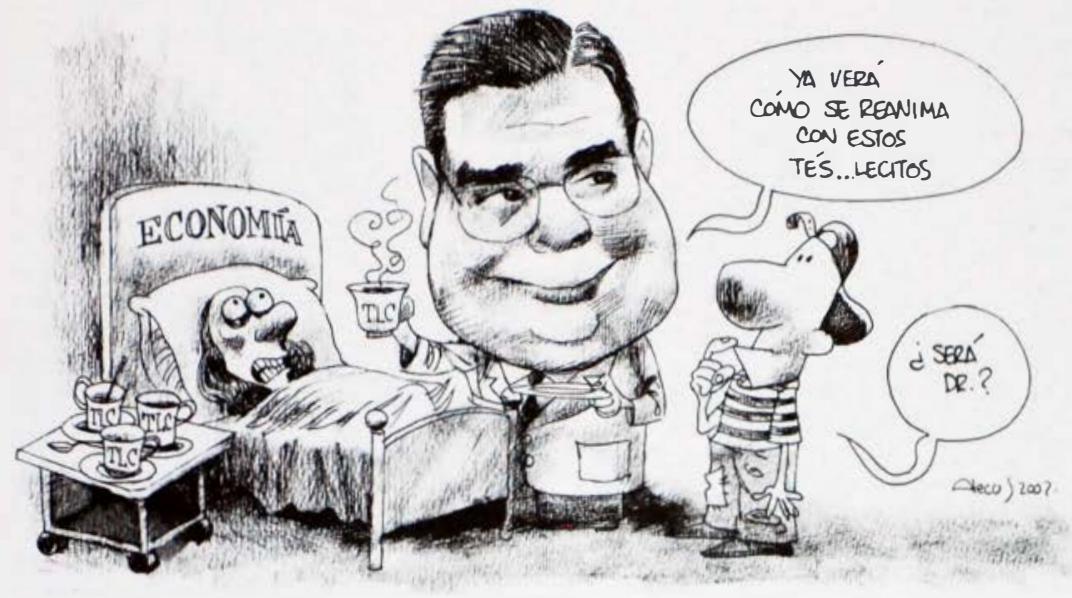

medianos ingresos, que ven reforzada su posición en el mercado. Pero las remesas también han propiciado deformaciones en el consumo, especialmente están creando variaciones en los patrones de comportamiento social que pueden ser conflictivos en los momentos en que las remesas fallen por cualquier causa.

De las escasas politicas definidas por el presente gobierno para combatir el desempleo se cuenta con la firma de tratados comerciales con diferentes países: México, Chile y Panamá. En el presente año se inician las primeras conversaciones para firmar un tratado con los Estados Unidos de América, que es uno de los mercados más apetecidos en el mundo.

Pero, los tratados comerciales, cualesquiera que sean $y^{\prime}$ con cualquier país, constituyen compromisos de doble vía. Se abren mercados pero con la obligada apertura del mercado local. La compecitividad, los costos de producción, los rendimientos, las economías de escala, se vuelven elementos claves para llevar productos al mercado. También es cosa sabida que en los países subdesarrollados, el costo de la mano de obra ha sido el atractivo principal por décadas para el establecimiento de inversiones, especialmente las maquilas.

Aquí aparece la otra política económica muy definida por las autoridades, como es el de la instalación de maquilas en el país, para promover el empleo. Pese a los incentivos ofrecidos, los medios informativos dieron cuenta de una reducción en la población ocupada en estas empresas durante el aino, por causa de una reducción de los contratos provocados, en primer lugar, por la recesión económica que mantuvo en vilo a la economía estadounidense durante todo el 2001 ; $y$ después por el ataque terrorista a las Torres Gemelas de Nueva York y el Pentágono, que afectaron la normalidad de las acrividades económicas por unos meses.

Recientemente México acepraba el cierre de 255 empresas de maquila durante el ario y la pérdida subsiguiente de $265 \mathrm{mil}$ empleos aproximadamente.

Nuestras autoridades han tenido que afrontar una situación similar $y$ hubo despidos de personal en las fábricas maquiladoras, pero se aseguró que la pérdida de empleo era de tipo temporal y que estos se reanudarían al establecerse los nuevos contratos.

Lamentablemente hay que señalar el cierre de una maquila japonesa, que clausuró sus operaciones en el mayor silencio $y$ huyeron del pais llevándose consigo las indemnizaciones laborales del personal que trabajaba con ellos. Sin duda, estos casos justifican las dudas sobre sí las maquilas son la respuesta correcta para superar el desempleo.

A partir del primero de enero del ario en estudio, se impuso la llamada Ley de Integración Monetaria, que 
convertía al dólar norteamericano en moneda de curso legal, obligando a todo el sistema bancario y financiero a manejar en dicha moneda todas sus operaciones. Al referirnos a esta medida, se hará caso omiso de los aspectos económicos para tocar únicamente su problemática social.

La primera situación a señalar, que todavía se mantiene, es la complicación en el manejo de las dos monedas mientras desaparece el colón salvadoreño. El problema no se da en los grandes centros comerciales sino a nivel del pequeño y micro comercio en los mercados. La adaptación de vendedores y compradores a ese nivel no ha sido fácil. Inicialmente las vendedoras se resistían a recibir los dólares, pues tenían el temor de ser engañados a la hora del pago y se necesita cierto nivel mínimo de educación para manejar una calculadora.

El otro problema fue el del redondeo, que aún subsiste, y que en alguna medida participa en un fenómeno de incremento de precios. El anclar el tipo de cambio en 8.75 colones por dólar, dificulta una conversión sencilla.

Las autoridades opinan que la integración monetaria ha sido un éxito, pues a la fecha el 51.2 por ciento del dinero circulante, equivalente a 532 millones de dólares, se encuentra participando en las transacciones financieras del país. Lo que se oculta es que los Bancos obligadamente pusieron en circulación dicha moneda al negarse tajantemente a satisfacer la demanda de colones de sus clientes. Sin duda, el Banco Central ha estado detrás de esta medida esterilizando y negando los colones demandados, pese a que la Ley suponía la libre participación de ambas monedas.

\section{La dimensión política}

I ejercicio de la política es sumamente complejo
porque es un actividad del poder; bien o mal entendido ese ejercicio no respeta límites, ya que estos en un momento dado, atentan contra el poder mismo.

Pese a que la Política es una ciencia y también un arte, en nuestro país ese juego en donde se combinan astucia, inteligencia, sabiduría y ética, entre otros muchos valores; queda reducido a una mueca de oportunismo, inmoralidad, absoluta carencia de valores éticos y una ignorancia evidente.

Para hacer un análisis de las características políticas del régimen de poder se requiere valorar en su propia dimensión y óprica, los hechos que en el transcurso del año identifican las tendencias seguidas por los que detentan el poder.

La corrupción generalizada es una de las principales formas para ejercer el poder; y esta situación se ha extendido como un cáncer en todas las capas de la sociedad salvadoreña.

ent 
La concertación, la negociación y conciliación de intereses nacionales no son mero juego de palabras en una democracia. Se considera que hay un grave error de apreciación. Concertar no significa debilidad, sino que es el ejercicio responsable del Estadista para garantizar equidad, transparencia, libertad e igualdad de oportunidades.

La complejidad de los Estados modernos forzosamente los lleva al establecimiento de sutiles relaciones de interdepen-dencia entre los aspectos económicos, sociales y politicos. Esta realidad no puede ser evadida y se pone de manifiesto cada vez que se hace necesario dictar una ley, establecer reglas del juego entre actividades o sectores, $y$ definir campos de autoridad.

Desde Montesquieu el equilibrio del poder se logra cuando el Estado se somete y funciona bajo la acción de tres Organos autónomos e indepen-dientes entre sí: el Ejecutivo, el Legislativo y el Judicial. En la medida en que cada uno de estos Organos cumple con su papel, la democracia es una realidad permanente.

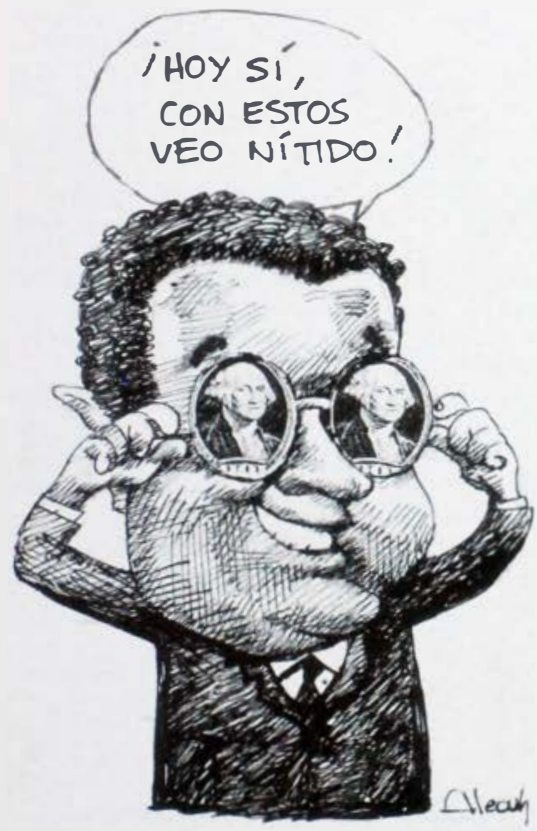

La gran interrogante es, esi en la realidad y no en apariencia, se ha logrado establecer el equilibrio de poderes necesario para mantener la democracia?. Especialmente preocupa la excesiva tardanza del Poder Judicial frente a sonadas demandas de inconstitucionalidad. Sin duda, una demanda de esta naturaleza implica a juicio de algunos ciudadanos, un deshorde en el límite del poder y no es aceptable tomarse todo el tiempo del mundo para resolverla.
«En las aristocracias se originan las sediciones porque son pocos los que participan de los honores, lo cual se ha dicho que altera también las oligarquias, por ser la aristocracia una especie de oligarquía»

Otra tendencia claramente definida en el campo político es dejar la solución de muchos problemas de interés nacional a lo que deje el tiempo. Esto es un indicador de aspectos que no se pueden o no se quieren resolver; pero todavía más impactantes son las razones profundas u ocultas que impiden las soluciones. A continuación se mencionan algunos temas, que en un entretejido de mutuas acusaciones, se hacen los políticos. Una Agenda de temas sin resolver son los siguientes:

El futuro del seguro Social, su eficiencia comosistema hospitalario y su papel en el régimen de pensiones;

- La legislación respecriva para impedir la operación de casinos en el país;

- Las regulaciones para la venta de licores en las ciudades;

El nuevo sistema de transportes, sus reglas de juego;

El tratamiento de la basura en el gran San Salvador;

El combate a las drogas, el secuestro y la corrupción.

El cambio social es dialéctico en su esencia y su naturaleza; pero además, debe ser dinámico y constructivo para que sea partícipe en la construcción de las nuevas sociedades. El cambio social es dialéctico aquí, en los Estados Unidos, en los países árabes, en la Venezuela de Chávez y en la Cuba de Fidel Castro. 
Las sociedades que se estancan estan condenadas a desaparecer, por la acción de las mismas fuer zas que en lugar de promover un cambio positivo se destruyen en la satisfacción de intereses exclusivos de grupos reducidos.

Cuando una sociedad se niega a reconocer los factores que entorpecen su camino hacia niveles de mejor bienestar social, de mayor democracia, de justicia, de equidad en todos los órdenes de la vida social se mueve dialécricamente hacia el autoritarismo, la dictadura, los gobiernos de clite; y se confurman los caldos de culrivos para que la dinámica social busque nuevos cauces de expresión y libertad.

\section{«Un príncipe corre a su ruina cuando quiere llegar a ser absoluto, especialmente si no gobierna por si mismo»}

Niccolo Machiavelli.

decir lo mismo de los países del Golfo Pérsico, de la Perestroika y el Glassnot, de las rebeliones de la Plaza de

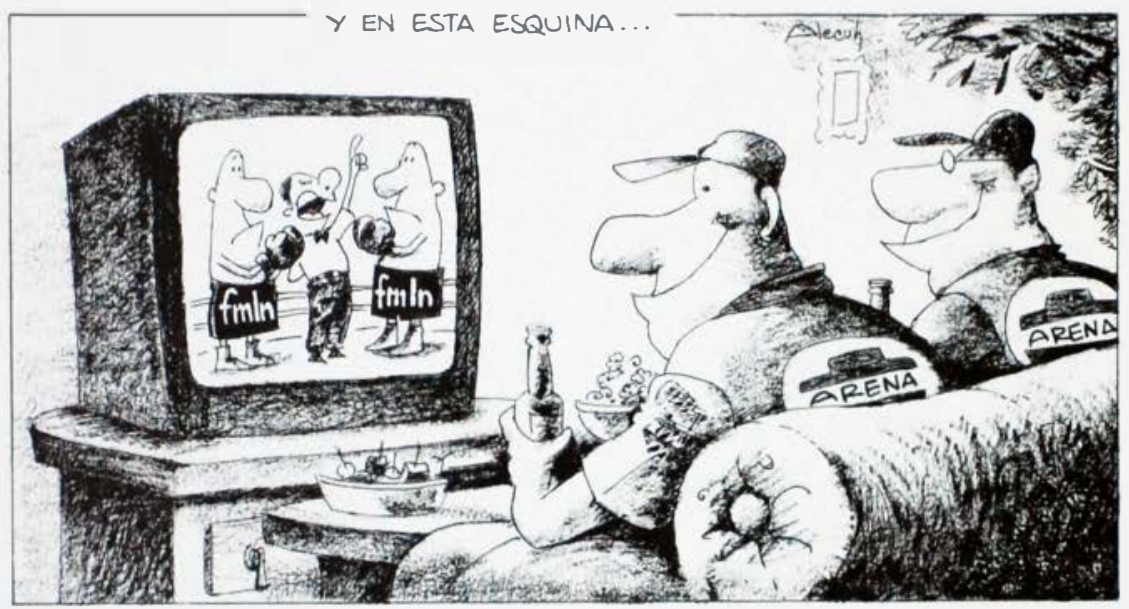

La Revolución Francesa fuc un cjemplo; lo mismo la independencia de las colonias de los imperios español, francés y norteamericano en América; la creación del Estado de lsrael. La Cuba castrista nació con el inicial aval de su pueblo contra la dictadura de Batista; y modernamente no podemos acaso

«A veces el valor de una cosa reside no en lo que con ella se alcanza, sino en lo que por ella se paga,... 》

Friedrich Nietzsche.
Tiananmen. En esta dialćctica no acaso el Presidente norteamericano busca nuevas relaciones con Rusia y China.

La dialéctica social es necesaria para comprender las intimas motivaciones de los pueblos, y su correcta lectura convierte al Presidente en Estadista. Las fuerzas sociales en este pais se mueven, $y$ lo hacen por distintas razones: por necesidad, por sobrevivencia, por bienestar, por superar las desigualdades y el nivel de pobreza.

Hemos tenido nuestra lección desde hace muchos años, la primera ofensiva data del 10 de enero de 1981, pero pareciera que nuestra memoria histórica es débil e inconstante. Pero eso también tiene un precio. ¡Ojalá no tengamos que pagarlo! En esta universidad todavía queremos apostarle a la esperanza. 